\title{
Meme language, its impact on digital culture and collective thinking
}

\author{
Yulia Petrova ${ }^{1 *}$ \\ ${ }^{1}$ Rostov State University of Economics, Bolshay Sadovay str., 69, Rostov-on-Don, 344002, Russia
}

\begin{abstract}
Memes have become an increasingly common form of modern communication, which has recently attracted great research interest. In this article we analyze "language - memes", its influence on digital culture and collective thinking. The Internet, by expanding social content, contributes to the variability of cultural codes and consequently changes an individual's cultural identity throughout life. The culture composed of cultural groups is defined as a kind of macro-code, consisting of numerous codes that are commonly used to interpret reality among members of the cyber community. Identity is also transmitted through the use of a specific language during interaction, which is a marker of discourse, in which Memes represent a distinctive business card. Linguists, as well as specialists in other disciplines (such as philosophy, anthropology) use each other's work to study the interrelationships and mutual influences of language and culture. The study proposed a hypothesis about the influence of the Internet on changes in society's thinking, the formation of the Internet culture and language, using the example of meme language, which is confirmed by the analysis of Internet survey. The interdisciplinary nature of the research is due to the use of mathematical method and the logic of meme language, its impact on digital culture and collective thinking, which is represented in the responses of respondents to the questions in online questionnaires.
\end{abstract}

\section{Introduction}

The theory of language and culture, developed in pre-cognitive linguistics and anthropology, has a long tradition, starting with linguo-philosophical concepts. V. von Humboldt characterizes culture and language as «mediating link between man and the world around him». Ferdinand de Saussure theorizes a synchronous approach to language, not only in a historical context, but also in a "relation to a specific moment" (regardless of the context of its development) [1]. In the study of language - memes of digital culture and collective thinking, as modern paradigms of our time, we adhere to the concept of the connection between thinking, language and culture, embedded in both communication and cultural models.

Internet communities are, first of all, communities, and second of all, online, as well as Internet culture, Internet language, - first of all, the culture and, second of all, the language.

${ }^{*}$ Corresponding author: julia-pp@,yandex.ru 
One of the components of the Internet language is the language of memes, which, according to the Cambridge English dictionary, consists of elements such as "cultural objects, images, videos, phrases, music ..." [2] etc.

Memes have a variety of functions, but mostly they are created and sent for the purpose of expressing opinion and creating emotion. According to Google Trends, the content of memes is understandable to every Internet user, regardless of age, language, culture, and nation. They are becoming an increasingly frequent search term, which indicates their growing popularity and location in the interval between national cultures or the identities of members of the cyber community. Their appearance in a daily online dictionary helps to strengthen strong relationships in the community. Not only do they cross languages, the link they create makes a sense of belonging among Internet users. Whether, they use "meme language" to express their feelings on certain issues or to heighten their obsession with famous celebrities. With the spread of memes, their exchange in the digital environment, there have been changes in communication. We can say that memes have contributed to globalization. The language of memes, as another type of communication (for example, verbal or non-verbal language) allows you to create relevant and stable representations (for example, bad, defective, unworthy, etc.), determines aspects of people's lives. In fact, its role in influencing the perception and communication of interlocutors remains one of the most popular introductory lines in both cultural linguistics and empirical studies on language and culture, online and offline communications. It has been argued in academic and analytical circles that memes, which have become a common spoken language, have a negative side, in cases where the communication is limited to the exchange of pictures, the use of memes to exacerbate hostile and prejudiced attitudes towards certain people, gender, religion, etc., which may contribute to the split between people. Thus, the given characteristics of memes are the exact opposite of globalization. The spread of meme language system elements, "fragments of digital content distributed over the network in different interpretations" [3] are attracting the interest of scientists in several fields (e.g., Bennett \& Segerberg (2012) [4]; Milner (2012) [5]; Spitzberg (2014) [6]) as well as the impact on language, culture and thinking by the ability to instantly share a meme.

In the colloquial speech of network users, the phrase "Internet meme" is usually used to describe the transmission of elements of content, such as jokes, rumors, videos or websites, from one person to another via the Internet. According to this popular representation, the Internet meme can spread in its original form, but often it also generates user-created derivatives [7], which can have an impact on users' Internet thinking and language, in a relationship and influence with culture.

Due to the growing dominance of the Internet as the primary means of communication, people are using more electronic media than ever before. And yes, the Internet, with its visual stimulation and constant distractions, is changing the way of thinking - and not always for the better. But, every new media that emerges on the scene raises similar concerns about harmful effects on tastes, thoughtfulness, and deep thinking. There is no doubt that the Internet has a profound impact on our lives, but in our opinion, its impact is as powerful as any technological invention since its inception. The advantage of any new technology is that it enhances human potential. In the 20th century, electricity, telephones, cars, airplanes, steamships made the world more accessible to more people, while changing the way society thinking. The Internet has the same revolutionary effect: people can overcome cultural barriers, including through the visualized language represented by memes. The visualized meme language is a communication system using visual elements that helps users perceive and understand visible signs. 


\section{Methods}

In an era in which social life is increasingly played out on the Internet, online and digital technologies have been used to collect and analyze meme language data used online survey. Digital research methods have made it possible to set different tasks and generate new data. In our study of "meme language", its influence on digital culture and collective thinking as a modern communicative paradigm of our time, the Internet has become the object of linguistic cultural production and transformation. According to Statista, the most common languages used on the Internet based on the proportion of Internet users as of 2020 are English, Chinese and Spanish. Other languages in the top ten, ranked third through tenth, include Arabic, Indonesian, Portuguese, French, Japanese, Russian, German [8].

While it is difficult to pinpoint exactly which languages will dominate in the future, there are some trends that can help predict the ranking today. The Internet is changing language faster than it has ever changed before. Internet conversations are structured in the form of applications and platforms and have a common "meme language". The linguistically inventive online community is spreading memes at a breakneck speed. Whereas the meme community is a coherent whole, memesis represents the way it works, contributes to the formation of a community by spreading its culture and language through the Internet.

Internet culture reflects a new area of language, placing it in the history of communication in the public sphere. Internet culture offers an analysis of the virtual world and the consequences of the mass thinking of society in a socio-technical environment, in which the Internet - culture, like the Internet - language poses certain space-time problems. The Internet does not imply a physical presence; a person is only co-present in the general "virtual" space of large-scale dimensions. The Internet involves an increasing number of participants, complements the almost unlimited possibility of archiving communicative materials in various forms. The field of our research, for the most part, has become a digital field: audio, video, messaging applications, other social networking platforms and meme image editors such as IMGFLIP, MAKE a MEME, CANVA, etc. that allows you to add text with a variable size to the images. They, like many others, work on canvas HTML5, so images are created instantly on the device. When working with an editor, people most often use generators to add text captions to created memes, and thus, technically, it looks more like a "follower" of memes than creating memes, although the option provided by the editor to upload their own images as templates is also popular. Thus, creating and modifying memes are an example of how people use the language of a meme to cope with all the hardships that life can bring. Creativity is not a separate process from critical thinking, it is connected together with philosophy, cultural studies and other humanities, contributed to the development of critical thinking, since the disciplines themselves in these areas create an environment that "encourages the production of meaning" [9].

There are several places where new memes emerge, the creation and dissemination of this visual language is carried out on every digital Internet platform that actively promotes memes in the process of interaction and user engagement, thus forming everyday discourse. An unambiguous opinion about the meanings of knowledge about the world under the influence of new information, consisting of concepts distinguished by the degree of complexity, which are of research interest in linguoculturology.

On the one hand, "this discipline should focus only on the study of cultural information, ...", on the other hand, linguoculturology "referring to the identification of human universals that can be found in linguistic and mental pictures, it should study living 
communicative processes in their synchronous connection with the mentality operating in a given cultural era" [10].

To achieve a specific goal in the study of memes, a number of methods, concepts, and approaches are used and combined. Through the analysis of visual techniques and various forms of qualitative data, we understand the real picture of the present, which is the basis for research and gain knowledge on this issue.

For cultural linguists, language acts, first of all, as "an expression of a special mentality". Of which, in linguoculturology, various methods of conceptual analysis are widely used, one of which is the "visual" method of R. Langaker [11]. At the same time, to analyze the cultural and linguistic communication of people in the Internet environment, using modern digital communications, the method of ethnography was applied, which makes it possible to understand social interaction in the context of modern digital communications - netnography [12]. A typical Meme consists of text and image, and thus both text and images are involved in the formation of the meaning of the meme. In addition, the "image-related attributes and textual attributes have significant incremental predictive power over each other" [13], and representing "wider social values and systems that shape the human condition" [14]. In the study of pandemic memes as a repository of social policy Sh. MacDonald used an approach that is based on "reading practice, which is built-in, context-dependent and interpreted" to actively "move through a web of connections" [15]. This approach makes it possible to distinguish emerging patterns from "disparate sets of instances" of memes in the digital environment. An Xiao Mina considers memes to be more than just an Internet phenomenon. The researcher notes that "it is difficult to overestimate the spread of memes in all spheres of life" [16]. If memes play an increasingly influential role in our social world, then we should consider them as an important object of scientific research at this moment of human experience. "... with their own well-established culture and norms." The analysis of memes "takes a fresh look at the modern Internet culture and the social consequences for the global audience of participants" [17].

Analysis of the online meme survey allows us to take a new look at modern digital culture, the thinking of individuals who use meme language.

\section{Results}

Language is the basic ability of the human brain for complex communication systems, which is necessary for the transfer of information between most autonomous subjects. The word "language" thus refers to a specific example of such communication. The language of memes in the Internet is a language that is mostly humorous, can be indirectly compared to non-verbal communication language. The use of humor has been discovered "in all social conditions throughout history and has led to attempts of the researchers to explain its philosophical foundations, different types" and what elements make it successful and why people are "motivated to consume" [18]. Perhaps memes represent an example of how people use humor in a given period of time, and perhaps over time they will be replaced, or become a permanent part of the Internet language, in scientific circles, the study of memes, the language of memes is at an early stage, as and the Internet language itself. Changes and additions taking place in the means of communication provide a prospect for further research, as well as aspects related to the Internet culture, which has greatly benefited from the invention and use of the Internet.

According to the information from the encyclopedia, communication in the philosophical sense refers to the "process of intellectual communication between people or groups, as a result of which there is a transfer and exchange of information, experience, attachments ...". In its usual use, "communication" refers to all means that serve to unite people through the dissemination of information ..." [19]. 21st century communication 
technologies such as: social networking platforms, e-mails, blogs, conferences communication, group forums, wearable technologies, etc. continue to grow rapidly.

The advent of the global Internet has made communication more democratic than ever, and has also shaped a new language of memes. It is very important to recognize the influence of the Internet on the thinking of society, language and culture. The study discusses its effects separately. Knowing the results can help make the Internet more useful by focusing on the accuracy of information and acknowledging its limitations. And also help preserve linguistic and cultural differences by learning about the importance of language and culture and by developing new ways of preserving identity, despite the influence of the Internet. The changes taking place in society's thinking, language and culture are just the beginning, and they may take many years to become fully operational. However, many of these changes, including those discussed in our study, are already evident, that the diagrams show.
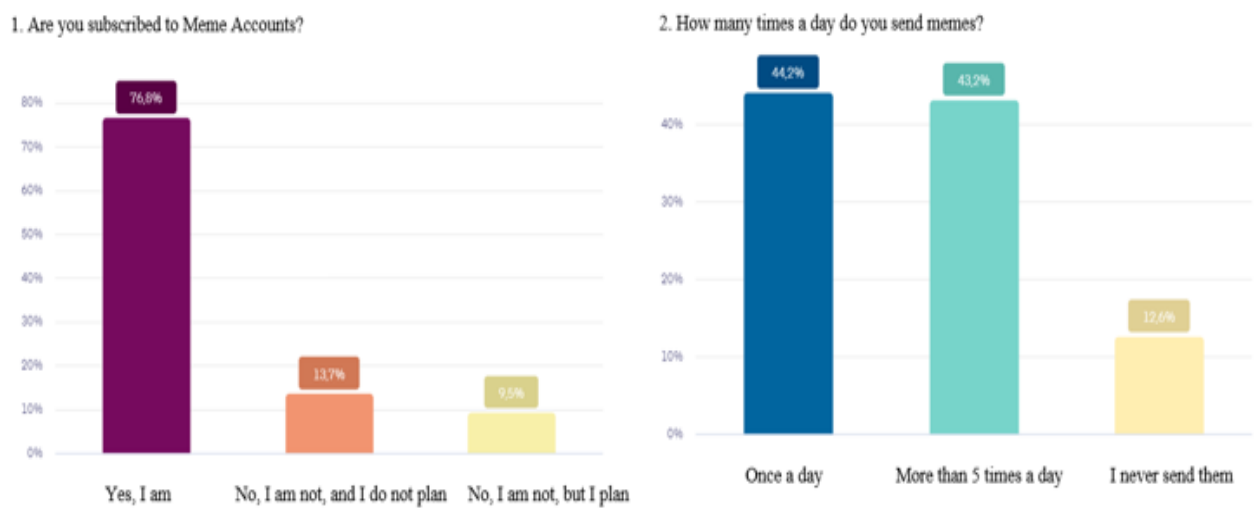

Fig. 1. Social Survey: The value of memes in language (created on the website https://www.survio.com).

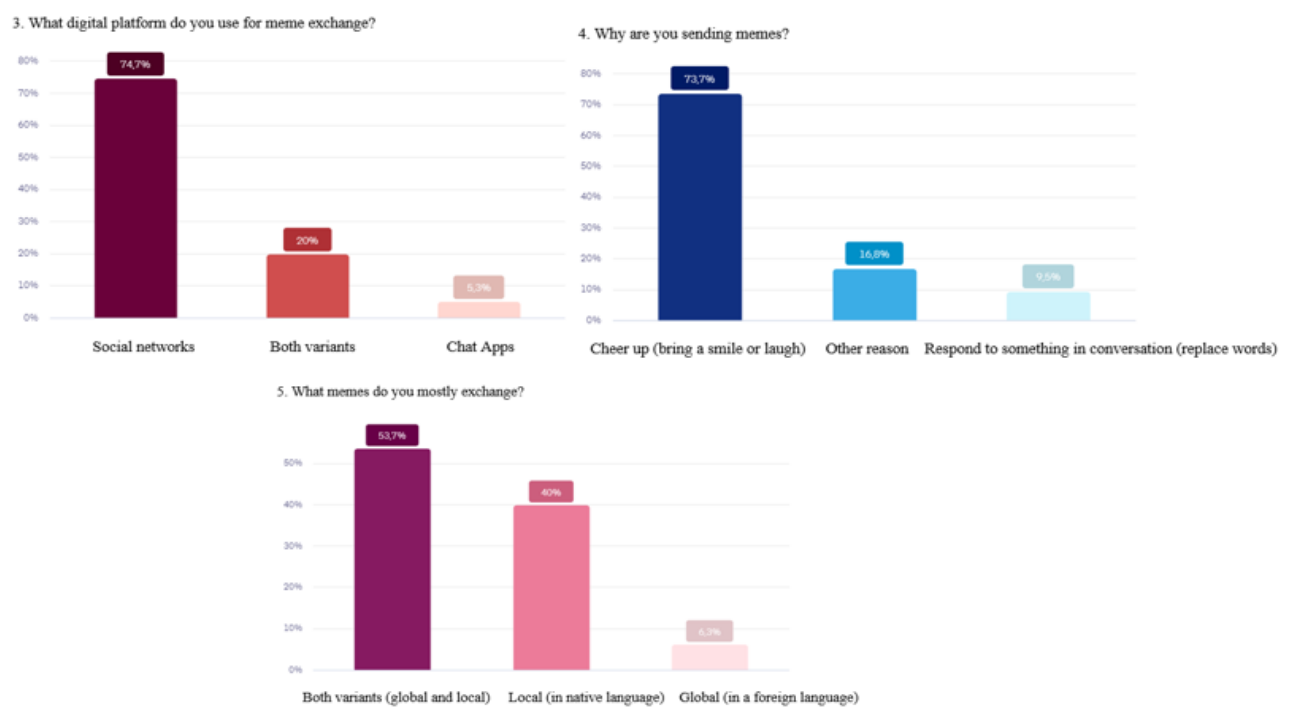

Fig. 2. Social Survey: The value of memes in language (created on the website https://www.survio.com). 
The assessment tool for this study was an online survey of 95 students (from 17 to 21 years old), of Rostov State University of Economics (RSUE). A balanced questionnaire offered respondents five closed (structured) subjective questions which are reflected in Fig.1 and Fig. 2. The results of the questionnaire analysis allowed us to make hypotheses about the modern communication paradigm. The first part of the hypothesis on the impact of the Internet on language, digital culture, and collective thinking is based on statistics on the use of memes, while the second part of the hypothesis is logically based on respondents' responses to each question in the survey.

As a result of our research of various ways of everyday communication of Internet users, we have found that $76.8 \%$ have already subscribed to meme accounts, $9.5 \%$ are more likely to be subscribed. The exponential growth of Internet accounts is also reflected in the high level of Internet user involvement. Almost 9 out of 10 respondents send memes every day, and almost every second $43.2 \%$ send memes more than five times a day. Most of the thinking on the Internet - communication people think in a short dialogue that gives their knowledge the qualities of openness, flexibility and creativity. Since only $12.6 \%$ of respondents tell us that they never shared memes, it is safe to say that the visual language of memes has influenced and continues to influence thinking and digital culture. According to our research, most of the visual language expression of Internet culture occurs on social networks $-74.7 \%$ of respondents said they share memes in social media, $20 \%$ said they use both as social networks, as chat apps, and only $5.3 \%$ said they shared memes only in chat apps. The speed with which young people share memes shows how important meme language is as a new means of communication. The speed at which memes are shared also helps to account the needs for new memes and their growth trends, because members of the culture of memes, although have their favorites, but still are constantly searching for something new. These new forms of communication, which are born out of a constant search for new and improved ways of communication, change what the conscious mind does - change thinking as a cognitive process.

So, we found out how many respondents send / share memes and where predominantly, what average number of memes they send every day but what role does the Internet play for respondents and which memes are preferred? According to our survey, the main reason that respondents use meme language is to cheer up, bring a smile or laugh $-73.7 \%$, use meme language to replace words and demonstrate participation in conversation - $9.5 \%$. Thus, memes don't just change the language of transferred words and expressions into an image; they also act as a comedy tool, as we see from the results of the survey, that's their most frequent target. This change of words reflects a desire for visual communication, which tends to grow and change the mindset of the representatives of digital culture. The spread of memes, continues to have a trend of popularity of memes in global (foreign) and local (native) languages $-53.7 \%$ of respondents (more than half of those surveyed) and 6.3\% prefer global one, $40 \%$ share only local memes. The survey shows a growing trend in global meme preferences.

The study is distinguished by at least three important aspects: level of analysis, direction of findings and conclusion.

\section{Discussion}

Cultural codes "as variants of invariant scheme" characterize membership of a cultural group, their influence on cultural identity, and have a tendency of constant development [20]. Identity is transmitted through the use of a specific language during interaction, which is a marker of discourse, in which Memes represent distinctive highlights.

The simplicity, conciseness and clarity of the message conveyed by memes are defined by the peculiar language of the cultural code, and demonstrate a cultural paradigm 
reflecting the thinking of society, which, especially in times of self-isolation and social distance, value entertainment and positive emotions, satisfying the needs to remain significant. The emotional form of imitation leads to the convergence of the emotional state of a person with the state of emotion of those with whom he/she interacts. That is, when online users watch Internet memes, they tend to experience the same emotions as their creators and distributors. The evolving intelligence of digital culture consumers is determined by the high level of awareness and understanding of Internet culture and language, which is evidence of their adaptive thinking and cognitive development. Memes - the building blocks of a language that is intertwined with culture, their availability and capacity are able to reach vast audiences, demonstrating the universality of quotation. The language of memes and the thought of people who live in different cultures have become integrated, and when they appear, something special begins to emerge.

Because of agencies and sociability of people, the spread of the Internet memes are much more than a simple imitation. This involves using familiar ideas and previous knowledge, and creating new combinations based on them, by remixing and then transforming different elements into a whole new one from what was copied earlier. Thus, memes can be characterized as an element of postmodernism that makes up meme languages and is interconnection and mutually complementary with Internet cultures.

\section{Conclusion}

If, historically, we could think of a community as a group of people living in the same place, with the same language and culture, which had already been defined, then the meme community is a whole, with a certain way of working. Memesis represents the process of creating a community by the spread of a new language, culture and thinking, in the communication model. So, language is a meme, not only showing how digital communities are changing the traditional structures of united people in a single space, but the way it indirectly adds people to the production itself, showing them as social beings, their thinking and culture.

For linguistic and culturally significant assessments, the linguocultural approach in the study made it possible to explore the aggregate that is derived from the originally created meme, as representing an innovative idea that contains the creative sense of the meme, to explore conceptualizations in which the sociocultural characteristics of society are manifested. Memes, defined in terms of ideas, thought or information, have been used in an attempt to explain the spread of new linguistic and cultural customs, changes in social thinking. Linguocultural concept made it possible to consider, as a model of meanings, the acquisition of meanings by interpreters by memes that connect the cyber community, in a single language and the Internet culture. Studies of language, culture, thinking and the influence of memes have shown that changes are taking place. The study revealed unique factors, the influence of memes not only on language and culture, but also on the thinking of modern society.

We do not exclude the possibility that the hypothesis we made about the peculiarities of meme language, its impact on digital culture and collective thinking - may be disproved. But, if future research succeeds in successfully replicating and expanding the results, especially in terms of the modern communication paradigm, this knowledge can be integrated into initiatives to improve cultural literacy and linguistic compliance on the Internet. Continuation of the study of the topic may encourage greater acceptance of certain behaviors and collective thinking, respect of the dignity of each Internet user, and not only, but also affirm the very value of shared thinking. 


\section{References}

1. B. Mitrovic, Philosophy for Architects (Princeton Architectural Press, New York, 2011)

2. Cambridge Dictionary,

URL: https://dictionary.cambridge.org/dictionary/english/meme

3. E. d Segev, A. Nissenbaum, N. Stolero, L. Shifman, Journal of Computer-Mediated Communication, 20(4), 417-433, (2015), DOI: https://doi.org/10.1111/jcc4.12120

4. L. Bennett, A. Segerberg, Information, Communication \& Society, 15(5), 739-768, (2012), DOI: https://doi.org/10.1017/CBO9781139198752

5. R. Milner, The world made meme: Discourse and identity in participatory media, $\mathrm{PhD}$ Thesis (University of Kansas, 2012)

6. H. B. Spitzberg, Communication Theory, 24(3), 311-339, (2014), DOI: https://doi.org/10.1111/comt.12042

7. L. Shifman, J. Comput-Mediat Comm., 18(3), 362-377 (2013), DOI: https://doi.org/10.1111/jcc4.12013

8. J. Johnson, Most common languages used on the internet as of January 2020, Statista, (2021), URL: https:/www.statista.com/statistics/262946/share-of-the-most-commonlanguages-on-the-internet/ (data accessed: 20.04.2021).

9. D. Dumitru, Studies in Higher Education, 44(5), 870-879 (2019), DOI: $10.1080 / 03075079.2019 .1586345$

10. Y. A. Petrova, Expression of the values of the youth subculture in the value-meaning space of the language (Publishing and Printing Complex RSUE, Rostov-on-Don, 2019)

11. Y. A. Petrova, Representation of values of youth subculture in the value-meaning space of the language, PhD Thesis, (Southern Federal University, Rostov-on-Don, 2012)

12. R.V. Kozinets, P.-Y. Dolbec, A. Earley, The SAGE handbook of qualitative data analysis, 262-276 (2014), DOI: https:/www.doi.org/10.4135/9781446282243.n18

13. K. Barnes, T. Riesenmy, M. Duc, E. Lleshi, N. Balogh, R. Molontay, Appl. Netw. Sci., 6(21) (2021), DOI: https://doi.org/10.1007/s41109-021-00358-7

14. L. Humphries, The qualified self: Social media and the accounting of everyday life (MA: MIT Press, Cambridge, 2018), DOI: 10.7551 / mitpress / 9780262037853.001.0001

15. S. MacDonald, Leisure Sciences, 43(1-2), 143-151 (2021), DOI: https://doi.org/10.1080/01490400.2020.1773995

16. M. A. Xiao, Memes to movements: How the world's most viral media is changing social protest and power (Beacon Press, 2019)

17. C. Carl, Habitus, 6-19 URL: http://citeseerx.ist.psu.edu/viewdoc/download?doi=10.1.1.363.7029\&rep=rep1\&type= pdf\#page=6) (data accessed: 15.04.2021).

18. C. Outley, S. Bowen, H. Pinckney, L. W. Black, Leisure Sciences, 43(1-2), 305-314 (2021), DOI: 10.1080/01490400.2020.1774449

19. C. Chen, Habitus, 6-19 (2012), URL: http://citeseerx.ist.psu.edu/viewdoc/download?doi=10.1.1.363.7029\&rep=rep1\&type= pdf\#page=6) (data accessed: 22.04.2021). 
20. New Catholic Encyclopedia. Communication, Philosophy of (2021), URL: https://www.encyclopedia.com/religion/encyclopedias-almanacs-transcripts-andmaps/communication-philosophy (data accessed: 18.04.2021).

21. Y. .Petrova, Representation of values of youth subculture in the value-meaning space of the language, PhD Thesis (Southern Federal University, Rostov-on-Don, 2012) 